\title{
Isolation and Molecular Identification of Aspergillus spp. Collected from Different Sources of Animals Feed
}

\author{
Ahmed D. Ahmed ${ }^{1 *}$, Nazar J. Al-Khafaji ${ }^{1}$ and Luma T. Ahmed ${ }^{2}$ \\ ${ }^{1}$ Branch of Microbiology College of Veterinary Medicine, University of Diyala, Diyala, Iraq \\ ${ }^{2}$ Branch of Microbiology College of Medicine, University of Diyala, Diyala, Iraq \\ *Corresponding author
}

\section{A B S T R A C T}

Aspergillus spp. is one of the most important fungal spp. In the mycology

Keywords

Compound feed,

Aspergillus species,

Molecular

identification

Article Info

Accepted:

23 May 2017

Available Online:

10 June 2017 kingdom and has many important medical, industrial and commercial interesting, it's one of the essential contaminants of food and feed especially under specific circumstances. Aspergillus species was isolated with other fungal species from different samples of feed used by the farmers in different places in the Diyala province such as Fusarium, Aspergillus niger, Aspergillus terrus, Penicillium species and purified in the especial agar media then DNA was successfully isolated from the Aspergillus spp. by using of a commercial kit. PCR was done by using two different primers NS1, C18 and ITS1, ITS4. The first primer sequence didn't give any result while the second primer revealed the amplification band of all isolated Aspergillus which improve the presence of the a flat oxigenic Aspergillus species in the 10 different feed samples.

\section{Introduction}

Among the fungal diseases Aspergillosis is one of the important fungal infections, which is caused by Aspergillus fumigatus and less commonly by other Aspergillus species (Richard 1991, Barnes and Denning, 1993). The warm, humid environment of the farm sheds, feed stores, floor etc., and favor its growth. The disease mainly affects the respiratory tract of the birds. It is the second more expensive health problem on an affected flock basis.

Fungi are continuous threat to livestock feeds of economic importance such as compound feeds. They may affect feed either directly by causing mechanical damage throughout feeding, or indirectly by secreting and spreading mycotoxins such as aflatoxins in the case of aflatoxin producing fungi.

Aflatoxins (AFs) are a group of mycotoxins produced as secondary metabolites by the spoilage of Aspergillus spp.

Particularly Aspergillus flavus and Aspergillus parasiticus (Davis and Diener, 1983; Miguel and Guillermo, 1986; Yu et al., 2003; Klich, 2007). 
These fungi can grow on various agricultural commodities and generate aflatoxins before and during harvest, handling, shipment and storage (Peraica et al., 1999; Giray et al., 2007; Reddy et al., 2009a). The most important members are aflatoxin B1 (AFB1), aflatoxin B2 (AFB2), aflatoxin G1 (AFG1) and aflatoxin G2 (AFG2). They are highly toxic and carcinogenic compounds that cause disease in livestock and humans (Richard, 2007). The International Agency for Research on Cancer (IARC) has clarified AFB1, AFB2, AFG1 and AFG2 in the group I as human carcinogens (IARC, 1993).

The common fungal genera contaminating compound feeds are those belonging to the Fusarium, Penicillium and Aspergillus genera. The predominant Aspergillus species are Aspergillus flavus and Aspergillus parasiticus elaborating the deterioration of compound feeds to reduced health and performance of those animals fed on such feeds.

They are ubiquitous in nature and for some time, have become an increasing cause of life threatening opportunistic diseases (Linden et $a l .$, 2003). These fungi proliferate in terms of growth and increased aflatoxin production, exhibiting high levels of disease pathogenicity in their diverse forms.

This has resulted in the growing interest in molecular biology of these fungi warranting acceleration in genomic research. Accurate identification of fungal pathogen is in many cases, a prerequisite for effective management of the diseases they cause and for ecological or population genetics studies (Gherbawy and Voigt, 2010). However, these fungal species are much more similar to each other and accurate identification to species level could not be possible. Hence, it is paramount that their morphological and molecular characteristics with respect to DNA presences are investigated, using the methods of fungal isolation and screening making use of macroand microscopic analysis, fungal DNA extraction, polymerase chain reaction (PCR) and an agarose gel electrophoresis.

Current advances in biotechnology, molecular genetic marker have been employed for rapid identification of different species of fungi (Lieckfeld and Seifert, 2000; Attanayake et al., 2009). Nevertheless, isolation of intact DNA is critical for a number of molecular analyses such as cDNA production and transcriptional output quantitation (Selma et al., 2008). Advancements towards identifying fungal species are by way of using DNA markers, developing DNA barcodes that are diagnostics of target species using speciesoligonucleotides (Druzhinina et al., 2005).

However, extraction processes of DNA from Aspergillus spp. depend on cell disruptions, nuclease inactivation and subsequently, the extraction of the molecule. A broad range of molecular manipulations of these fungi are now possible. These include gene disruption, PCR and Real time PCR (RT-PCR) applications as well as DNA based epidemiological studies (Jin et al., 2004). Each of these techniques requires the recovery of good-quality genomic DNA.

From above we decide to isolate the pure culture of $A$. flavus from feed of animal in addition to using molecular technique for detection of DNA.

\section{Materials and Methods}

\section{Fungal isolation}

Samples of different sources of compound animals feed were collected from many towns of diyala province / Iraq.

$20 \mathrm{~g}$ of feed were taken and made two form the first by ground them as powder, the second by made suspension with $5 \mathrm{ml}$ PBS. 
Then inoculate on potato dextrose agar (PDA) agar 7 days in $(25-27){ }^{\circ} \mathrm{C}$. We have many fungi species were grown. In the present study detect Aspergillus flavus by macroscopic detection and further subculture of Aspergillus spp. To purified the fugal spp.

\section{Molecular analysis}

\section{Fungal DNA extraction}

Isolates of pure fungal strains for DNA extraction were subculture don potato dextrose agar (PDA) agar medium and incubated for 5 days at $25^{\circ} \mathrm{C}$. The extraction of DNA was performed using a DNA extraction Mini kit according to the manufacturer's (Promega DNA extraction kit) modified protocol. The purified DNA was stored at $20^{\circ} \mathrm{C}$ until further analysis.

PCR reaction to amplify the gene of aflatoxinproducing Moulds was done according to the manufacturer procedure to amplify the tamplate DNA with ITS1 [TCCGTAGGTGAACCTGCGG] and ITS4 [TCCTCCGCTTATTGATATGC]. Individual reactions had $10 \mu \mathrm{l}$ Go Taq, Green master mix $2 \mathrm{X}$ (promega, USA), $1 \mu \mathrm{l}(10 \mathrm{nM})$ for each forward and reverse primers, $4 \mu \mathrm{l}$ of purified DNA $(8-25) \mathrm{ng}$, in $20 \mu \mathrm{l}$ of total reaction volume.
Initial Denaturation $95{ }^{\circ} \mathrm{C}$ for 5 min was Followed by 35 cycles of $95^{\circ} \mathrm{C}, 55^{\circ} \mathrm{C}$, and $72^{\circ} \mathrm{C}$ and Final Extension was carried at $72^{\circ} \mathrm{C}$ for $7 \mathrm{~min}$, reaction tubes were holding at $4^{\circ} \mathrm{C}$ as final steps of PCR amplification.

\section{Results and Discussion}

The present study revealed typical colonies of Aspergillus flavus colonies with other fungal species (mixed culture) after culturing of feed samples in 2 different preparation powder and phosphate buffer solutions (Fig. 1). Subculture of the resulted Aspergillus flavus was done as shown in figure 2 . The same results demonstrated by major data indicated that 67.5 and $51.1 \%$ of feed samples were found to be contaminated with A. flavus and A. parasiticus, respectively. Accordingly, poultry feed had the highest contamination mean level (Mohankumar et al., 2010; Godet and Munaut, 2010).

One of the corn samples presented the highest fungal load in malt extract media, The other corn sample presented lower fungal load (2 $\mathrm{CFU} / \mathrm{g}$ MEA - $6 \mathrm{CFU} / \mathrm{g}$ DG18) and in addition to $F$. graminearum (2 CFU/g MEA $5 \mathrm{CFU} / \mathrm{g}$ DG18), isolates from A. ochraceus complex and Penicillium genus were also detected(Viegasetal.,2015).

Fig.1 Show mixed culture of fungal sp.

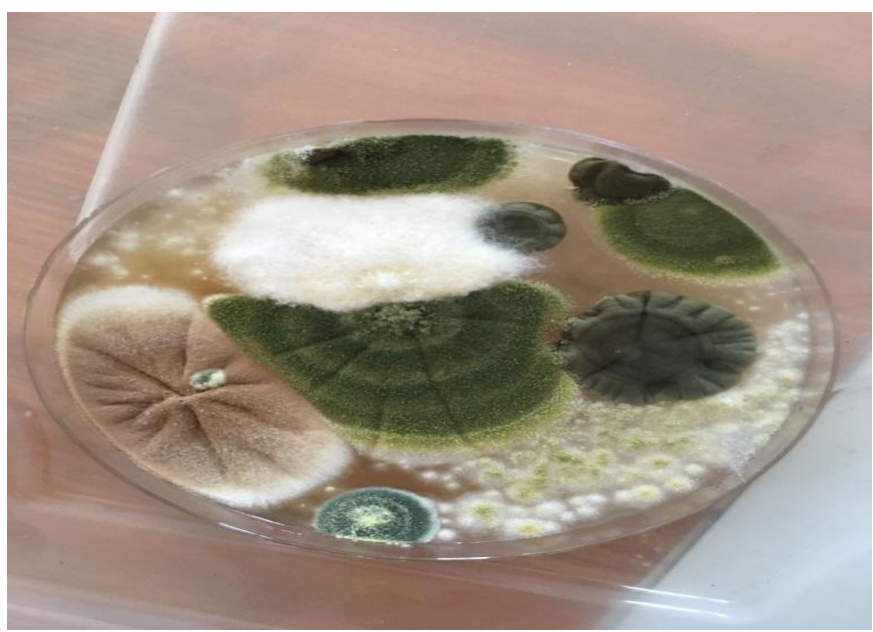


Int.J.Curr.Microbiol.App.Sci (2017) 6(6): 1792-1797

Fig.2 Pure culture of Aspergillus flavus

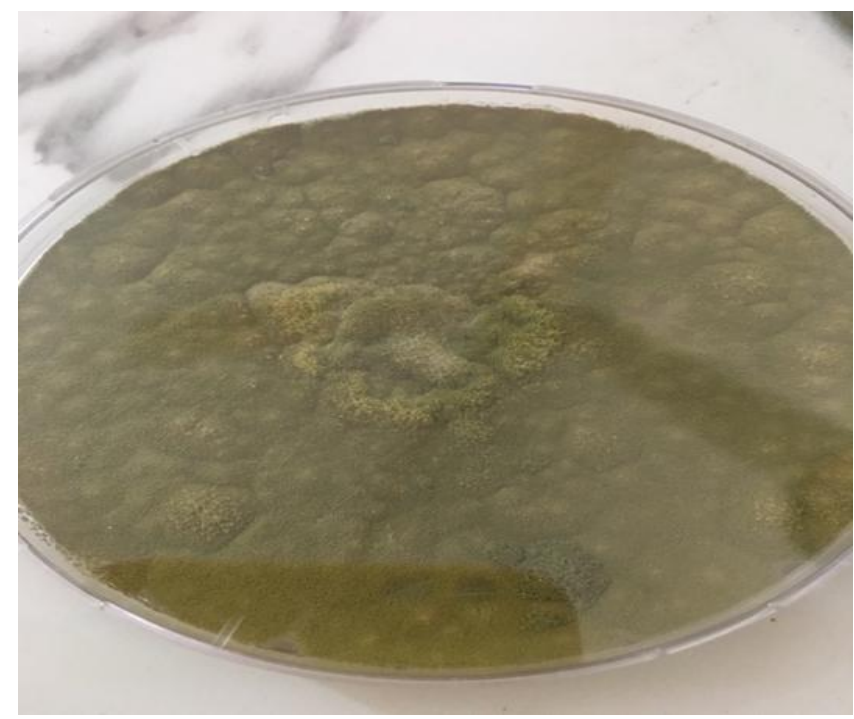

Fig.3 Positive result with primer: ITS1 and ITS4

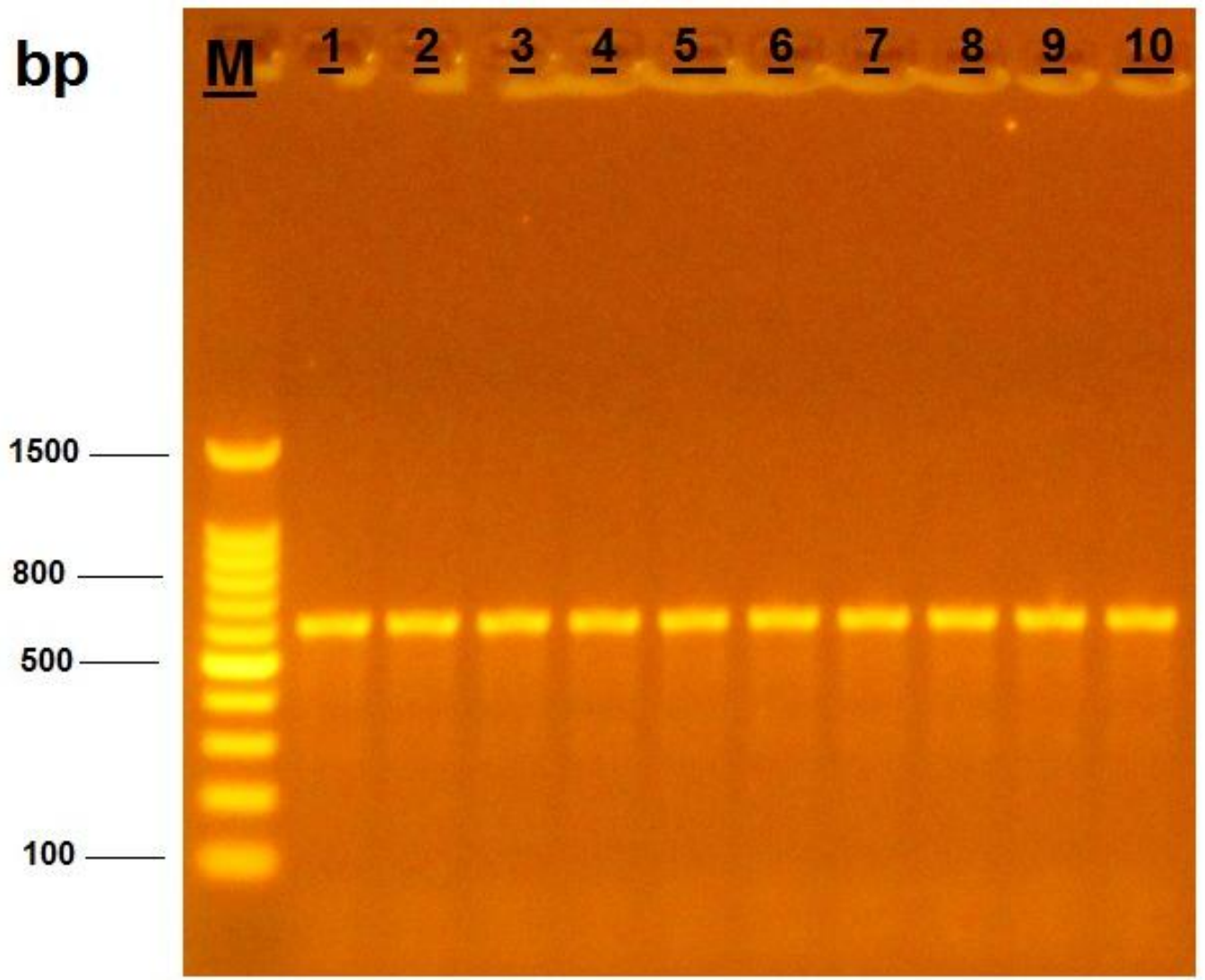


Fig.4 Negative result with the primer NS1 and C18L

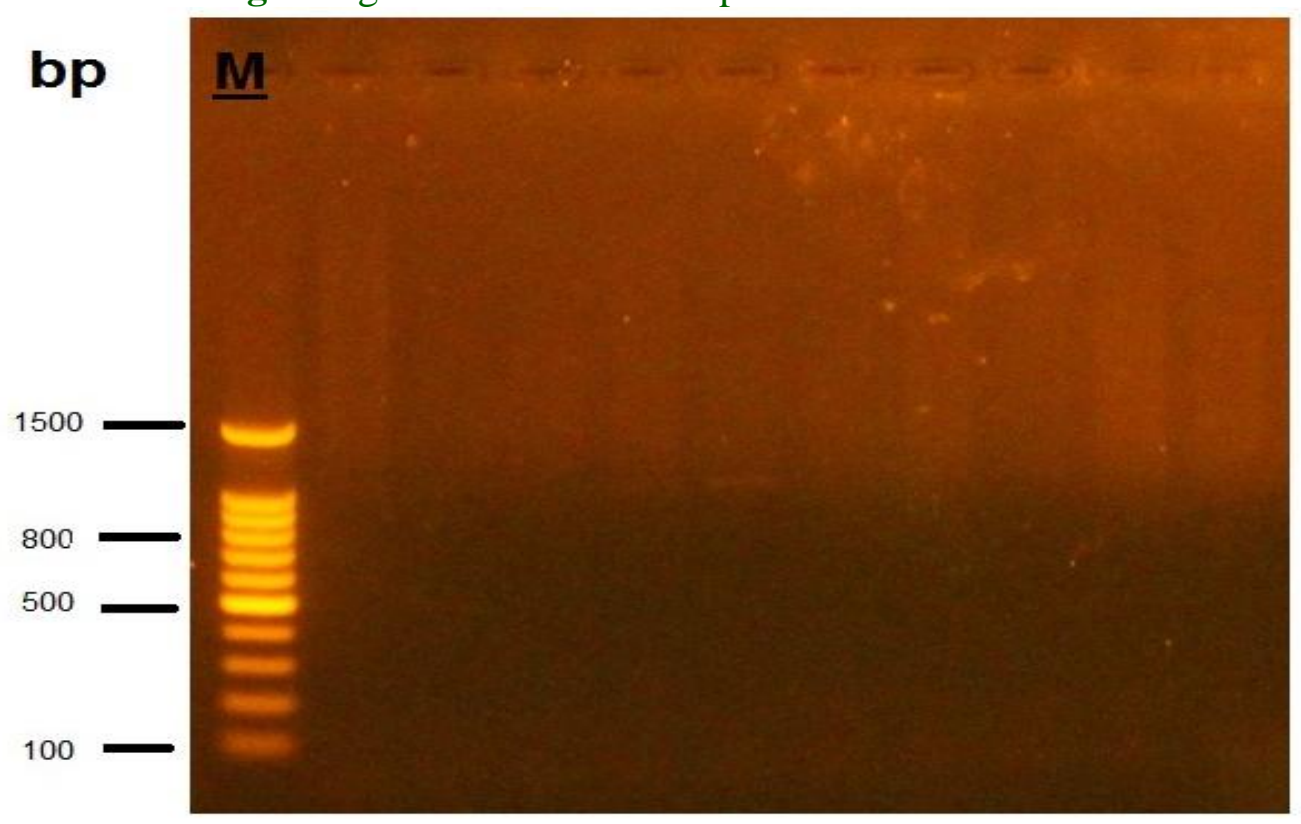

In addition, the results of DNA identification revealed the presence of aflatoxigenic Aspergillus species by using the primers ITS1 and ITS4 with the second primers NS1 and C18L, the results were negative by using the second primers while positive were with first primers which are the same used in the study of Temu in 2016 which Total genomic DNA of selected Aspergillus strains showing all four or three aflatoxin biosynthetic genes were sent to Inqaba Biotec, South Africa (Figs. 3 and 4). The negative results may be attributed to the isolate species not genetically same that could detected by NS1 and C18L or a mutation does occurred with the isolated species so changed the nucleotide sequence and not associated with the mentioned primer. DNA nucleotide sequencing of $5.8 \mathrm{~S}$ -ITS rRNA gene was done by using chain terminator method using ITS1 and ITS4primers.based on a $600 \mathrm{bp}$ fragment corresponding to the amplification of the ITS1/5.8S/ITS2 region with the primer pair ITS1-ITS4 (Viegas et al., 2015).The same results was found in the study deals with the identification of Candida species by the same primer ITS1 and ITS4 (Yuan
etal.,2012).In addition to identification of Yarrowia lipolytica DNA by using the same primers ITS1 and ITS4, the isolate is isolated from raw and processed poultry (Deak et al., 2000). Aflatoxins may be produced but not detected because of the inherent detection limits of the analytical Systems (Viegas et al., 2015).This field is rapidly expanding and the goal of these measurements is the assignment of risk to an individual from an exposure(Lee eta., 2016).

\section{References}

Attanayake, R.N., Glawe, D.A., Dugan, F.M., Chen, W., Erysiphe trifolii causing powdery mildew of lentil (Lens culinaris). Plant Dis.. 2009. 93, 797e803.

Barnes, A. J. and D. W. Denning. (1993) Aspergilli-Significance as pathogens. Rev. Med. Microbiol., 4.176-180.

Davis, N.D., Diener, U.L. Some characteristics of toxigenic and nontoxigenic isolates of $A$. flavus and A. parasiticus. In: Diener,U.L., Asquith, R.I., Dickens, J.W. (Eds.), Aflatoxin and A. flavus in Corn, Southern Coop Ser Bull Alabama AgricExpStavol, 1983.279, pp.1-5. 
Deak, T., J. Chen, and L. R. Beuchat. Molecular Characterization of Yarrowia lipolytica and Candida zeylanoides Isolated from Poultry. Applied and Environmental Microbiology.2000, Oct.p. 4340-4344.

Druzhinina, I.S., Kopchinskiy, A.G., KomonZelazowska, M.,. An oligonucleotide barcoden for species identification in Trichoderma and Hypocrea. Fungal Genet. Biol. 2005. 42, 813e828.

Gherbawy, Y., Voigt, K.,. Molecular Identification of Fungi. Springer. Ghiasian, S.A., Maghsood, A.H., 2011. Occurrence of aflatoxigenic fungi in cow feeds during the summer and winter season in Hamadan, Iran. Afr. J. Microbiol. Res. 20105.,516e521.

Giray, B., Girgin, G., Engin, A.B., Aydm, S., Sahin, G., Aflatoxin levels in wheat samples consumed in some regions of Turkey. Food Control. 2007.18, 23-29.

IARC,. Food items and constituents, heterocyclic aromatic amines and mycotoxins. In: IARC monographs on the evaluation of carcinogenic risks to humans, 56. International Agency for Research on Cancer.1993 (pp. 489-521).

Jin, J., Lee, Y.K., Wickes, B.L.,. Simple chemical extraction method for DNA isolation from Aspergillus fumigatus and other Aspergillus species. J. Clin.Microbiol. 2004.42:4293-4296.

Klich, M.A.,. Aspergillus flavus: the major producer of aflatoxin. Mol. Plant Pathol. 8, 713-722. Mycopathologia. 200795, 129132.

Lee, E., A. Kim, E. Lee, S. Park, K. Jeong. Septic shock associated with complex infection by crop Candida and bacteria in two blue-fronted amazon

Lee, E., A. Kim, E. Lee, S. Park, K. Jeong. Septic shock associated with complex infection by crop Candida and bacteria in two blue-fronted amazon

Lieckfeld, E., Seifert, K.,. An evaluation of the use of ITS sequence in the taxonomy of the Hypocreates. Study Mycol., 2000. 35e44.

Linden, P.K., Coley, K., Fontes, P., Fung, J.J., Kusne, S.,. Invasive aspergillosis in liver transplant recipients: outcome comparison of therapy with amphotericin B lipid complex and a historical cohort treated with conventional amphotericin B. Clin. Infect. Dis.,. 2003. 17e25.

Miguel, A.M.R., Guillermo, S.F. Aflatoxinproducing potential of Aspergillus flavus strains isolated from Spanish poultry feeds 1986.

Parrots: a case report Veterinarni Medicina, 2016.61, (5): 288-294.

Peraica, M., Radic, B., Lucic, A., Pavlovic, M.,. Toxic effects of mycotoxins in humans. Bull. World Health Org. 1999.77, 754-766.

Reddy, K.R.N., Saritha, P., Reddy, C.S., Muralidharan, K., Aflatoxin B1 producing potential of Aspergillus flavus strains isolated from stored rice grains. Afr. J. Biotechnol. 2009c. 8, 3303-3308.

Richard., J. L., (1991) Aspergillosis In: Disease of Poultry. $9^{\text {th }}$ ed. B.W. Calnek, H.J. Barnes, C.W. Beard. W.M. Reid, and H.W.Yoder, Jr., eds. Iowa State University Press. Ames, Iowa, PP. 326-334.

Viegas C., R. Sabino and S. Viegas. Feed contamination by potential toxigenic fungi and of A. flavus complex. in Toxicology Letters. 2015. September 238(2).

Yuan Wu, Peng-Cheng Du, Wen-Ge Li, JinXing Lu. Identification and Molecular Analysis of Pathogenic Yeasts in Droppings of Domestic Pigeons in Beijing China, Mycopathologia.2012. 174:203-214.

\section{How to cite this article:}

Ahmed D. Ahmed, Nazar J. Al-Khafaji and Luma T. Ahmed. 2017. Isolation and Molecular Identification of Aspergillus spp. Collected from Different Sources of Animals Feed. Int.J.Curr.Microbiol.App.Sci. 6(6): 1792-1797. doi: https://doi.org/10.20546/ijcmas.2017.606.208 